\title{
Modelling and analysis of CVD processes for ceramic membrane preparation
}

\author{
H.W. Brinkman, G.Z. Cao, J. Meijerink, K.J. de Vries and A.J. Burggraaf \\ Laboratories of Inorganic Chemistry, Materials Science and Catalysis, Department of Chemical Technology, \\ University of Twente, P.O. Box 217, 7500 AE Enschede, The Netherlands
}

\begin{abstract}
A mathematical model is presented that describes the modified chemical vapour deposition (CVD) process (which takes place in advance of the electrochemical vapour deposition (EVD) process) to deposit $\mathrm{ZrO}_{2}$ inside porous media for the preparation and modification of ceramic membranes. The isobaric model takes into account intrapore Knudsen diffusion of $\mathrm{ZrCl}_{4}$ and $\mathrm{H}_{2} \mathrm{O}$, which enter the membrane from opposite sides, and Langmuir-Hinshelwood reaction of the solid product $\mathrm{ZrO}_{2}$ on the internal pore wall. The processes occurring in one single pore are investigated, and the change in pore geometry during deposition is taken into account. Based upon this model, the deposition profile is studied. The model fits reasonably well with experimental results.
\end{abstract}

\section{Introduction}

The combination of the modified chemical vapour deposition (CVD) process and the electrochemical vapour deposition (EVD) process is originally applied by Westinghouse Electric Co. to grow dense yttria-stabilized zirconia (YSZ) layers on porous substrates [1]. The principles of the CVD/EVD technique have been outlined in detail elsewhere [13 ]. Only a limited number of studies has been reported solely on the CVD part of the process, for instance [3-6]. This stage is even more important since its result is determining for the EVD formed layers, especially in the case that ultra thin $(<1 \mu \mathrm{m})$ and dense layers have to be produced. The CVD stage regulates the deposition of solid product on the inside pore walls; this penetration can be considerably large. Beside others, an important application for these very thin layers of solid electrolyte (or mixed conducting) materials is the use as oxygen separation membranes. In the case that diffusion of oxygen ions through the layer is the rate limiting step in the separation process, dense membrane layers should be as thin as possible to obtain a maximum electrochemical oxygen permeation rate.

In this paper a mathematical model is presented to describe the CVD process for deposition of $\mathrm{ZrO}_{2}$ inside a porous $\alpha$-alumina substrate, with a thickness of $2 \mathrm{~mm}$, an average pore radius of $80 \mathrm{~nm}$ and a porosity of $50 \%$. An extensive outline of the model is given, followed by (numerical) simulation results. The influences of temperature, reactant concentrations and boundary conditions are evaluated. At the end, modelling results are compared with experimental results from electron dispersive $\mathrm{X}$-ray analysis (EDX).

\section{Modelling of the CVD process}

In the CVD/EVD process $\mathrm{ZrCl}_{4}$ and $\mathrm{YCl}_{3}$ on one hand, and $\mathrm{H}_{2} \mathrm{O}$ on the other hand, are delivered from opposite sides into a porous substrate. Inside or on this substrate they react to YSZ, as can be seen in e.g. ref. [7]. Since the YSZ composition contains about $90 \% \mathrm{ZrO}_{2}$, most of the reaction is in the form of:

$\mathrm{ZrCl}_{4}+2 \mathrm{H}_{2} \mathrm{O} \rightarrow \mathrm{ZrO}_{2}+4 \mathrm{HCl}$.

Only this reaction is taken into account for the model.

Diffusion and reaction take both place inside a pore which is considered to have a cylindrical shape. A schematical view of the CVD process is given in fig. 1. It is assumed that the vapour concentration does not change in the radial direction $\left(\mathrm{d} J_{i} / \mathrm{d} r=0\right)$. This assumption is valid since the pore length is much larger than its radius. The pore radius $r$ is a function 


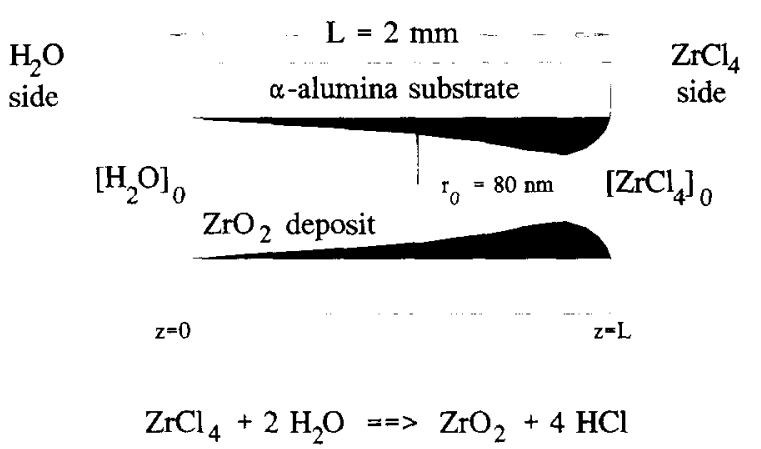

Fig. 1. Schematic model for the CVD process in a cylindrical pore.

of axial pore position $z$ and time $t$, since the reaction product is a solid material that deposits on the pore wall. The mass balance in the unsteady state for compound $i\left(\mathrm{ZrCl}_{4}\right.$ or $\left.\mathrm{H}_{2} \mathrm{O}\right)$ is in this case:

$\frac{\mathrm{d}\left([i] r^{2}\right)}{\mathrm{d} t}=-\frac{d\left(J_{i} r^{2}\right)}{\mathrm{d} z}-R_{i} r^{2}$.

Expressions have to be found for fluxes $J_{i}$ and reaction rates $R_{i}$. No pressure gradient exists over the substrate, so only diffusive fluxes have to be taken into consideration.

\subsection{Diffusion regime and reaction mechanism}

During the CVD process, deposition takes place on the pore surface and so the pore radius decreases spatially. In the beginning of the CVD process, e.g. when the pore has its largest size (average radius 80 $\mathrm{nm}$ ), the Knudsen diffusion regime holds for $\alpha$-alumina substrates at high temperatures $(800$ $1000^{\circ} \mathrm{C}$ ) and low pressure $(2 \mathrm{mbar})$. The Knudsen number, which is the ratio of the mean path way of the diffusing particles and the average pore diameter, is under the abovementioned process conditions in the range 200-2000; this is much larger than 10, the limiting value for the Knudsen regime [8]. When the CVD process further proceeds, the Knudsen number will increase. The diffusion regime is also checked by the kinetic collision theory [9]; the number of collisions of the particles under consideration with the pore wall is a factor $10^{3}-10^{4}$ larger than the number of intermolecular collisions.

Surface diffusion will also be excluded from the model, because according to ref. [10] this kind of diffusion does not occur as the partial pressure of the reacting species is low, the temperature is sufficiently high and the total pressure is low. These demands are all satisfied in the CVD process. Micropore diffusion is also not taken into account in the model since only when the pore diameter decreases below $2.5 \mathrm{~nm}$ the influence of the potential field of the pore wall becomes predominating [11].

So in a first approximation only the Knudsen diffusion is taken into account. In ref. [12] a derivation is given of Knudsen diffusivity in a cylindrical capillary of radius $r$, neglecting end effects. In $\alpha$-alumina substrates the ratio $L / r=25000$, which means that end effects can be neglected. This leads to the following equation for the flux of compound $i\left(\mathrm{ZrCl}_{4}\right.$ or $\mathrm{H}_{2} \mathrm{O}$ ) in a cylindrical pore [13]:

$J_{i}=-D_{\mathrm{Kn}, i} \frac{\mathrm{d}[i]}{\mathrm{d} z}$ with $D_{\mathrm{Kn}, i}=\frac{2}{3} r_{i}$.

In real porous samples, the pores are not cylindrical; a certain effective diffusion coefficient is necessary which includes the influence of the real geometry of the sample. This is often done by incorporating the porosity $\epsilon$ (correction for the free space that is available for diffusion) and tortuosity $\tau$ (correction for the shape of the pore) of the substrate [14]:

$D_{\mathrm{eff}, i}=\frac{\epsilon}{\tau} D_{\mathrm{Kn} . i}$.

The reaction of $\mathrm{ZrCl}_{4}$ and $\mathrm{H}_{2} \mathrm{O}$ inside a porous substrate can occur in a way that is limited by two extreme models: (1) a homogeneous reaction between the reactants in the gas phase, after which the product deposits on the pore surface; this will in general give a porous, crystalline deposition; (2) a heterogeneous reaction between the reactants of which at least one is adsorbed on the pore surface. As is mentioned before, during the CVD process the frequency of molecules colliding with the pore wall is much larger than with each other. So it is most likely that in this regime (high temperature, low pressure, small pores) a heterogeneous surface reaction occurs. In this case the following steps will take place: adsorption of $\mathrm{ZrCl}_{4}$ and $\mathrm{H}_{2} \mathrm{O}$ on the pore surface, followed by a surface reaction between the adsorbed species and crystallization of the formed $\mathrm{ZrO}_{2}$. At high temperatures adsorption equilibrium is assumed between the gaseous reactants and the ad- 
sorbed species; the surface reaction will be rate limiting. This kind of reaction is known as the Langmuir-Hinshelwood reaction [15]:

$R_{\text {surf }}=k_{\text {surf }}\left[\mathrm{ZrCl}_{4 \text { ads }}\right]^{N}\left[\mathrm{H}_{2} \mathrm{O}_{\text {ads }}\right]^{M}$.

In this equation the effect of the product gas $(\mathrm{HCl})$ is not incorporated since the conditions of the reaction are such that the concentrations are low. The concentration of adsorbed molecules can be correlated to the concentration in the gas phase (assuming uniform concentration over the pore cross-sectional area) according to [15]

$$
\begin{gathered}
{\left[\mathrm{ZrCl}_{4 \text { ads }}\right]=\frac{K_{\mathrm{ZrCl}_{4}}\left[\mathrm{ZrCl}_{4}\right]}{1+K_{\mathrm{ZrCl}_{4}}\left[\mathrm{ZrCl}_{4}\right]+K_{\mathrm{H}_{2} \mathrm{O}}\left[\mathrm{H}_{2} \mathrm{O}\right]},} \\
{\left[\mathrm{H}_{2} \mathrm{O}_{\mathrm{ads}}\right]=\frac{K_{\mathrm{H}_{2} \mathrm{O}}\left[\mathrm{H}_{2} \mathrm{O}\right]}{1+K_{\mathrm{ZrCl}_{4}}\left[\mathrm{ZrCl}_{4}\right]+K_{\mathrm{H}_{2} \mathrm{O}}\left[\mathrm{H}_{2} \mathrm{O}\right]} .}
\end{gathered}
$$

In the case of the CVD process the conditions are such that $K_{\mathrm{ZrCl}_{4}}\left[\mathrm{ZrCl}_{4}\right]$ and $K_{\mathrm{H}_{2} \mathrm{O}}\left[\mathrm{H}_{2} \mathrm{O}\right]$ are negligible compared to unity. Eqs. (5) and (6) are simplified to:

$$
\begin{aligned}
& {\left[\mathrm{ZrCl}_{4 \text { ads }}\right]=K_{\mathrm{ZrCl}_{4}}\left[\mathrm{ZrCl}_{4}\right] \text {, }} \\
& {\left[\mathrm{H}_{2} \mathrm{O}_{\text {ads }}\right]=K_{\mathrm{H}_{2} \mathrm{O}}\left[\mathrm{H}_{2} \mathrm{O}\right] \text {. }}
\end{aligned}
$$

The overall reaction rate is now

$$
R_{\text {surf }}=k_{\text {surf }} K_{\mathrm{ZrCl}_{4}}^{N} K_{\mathrm{H}_{2} \mathrm{O}}^{M}\left[\mathrm{ZrCl}_{4}\right]^{N}\left[\mathrm{H}_{2} \mathrm{O}\right]^{M} \text {. }
$$

The surface reaction constant $k_{\text {surf }}$ and the adsorption equilibrium constants $K_{\mathrm{ZrCl}}$ and $K_{\mathrm{H}_{2} \mathrm{O}}$ are a function of temperature via the Arrhenius and Van 't Hoff equations

$$
\begin{aligned}
K= & k_{\text {surf }} K_{\mathrm{ZrCl}_{4}}^{N} K_{\mathrm{H}_{2} \mathrm{O}}^{M}=k_{0, \text { surf }} \exp \left(-E_{\mathrm{act}} / R T\right) K_{0, \mathrm{ZrCl} 4}^{N} \\
& \times \exp \left(-N \Delta H_{\mathrm{ZrCl}_{4}}^{\mathrm{ads}} / R T\right) K_{0, \mathrm{H}_{2} \mathrm{O}}^{M} \\
& \times \exp \left(-M \Delta H_{\mathrm{H}_{2} \mathrm{O}}^{\text {ads }} / R T\right) .
\end{aligned}
$$

Since the surface reaction rate increases exponentially with the temperature and the adsorption constants will decrease with increasing temperature in most cases $\left(\Delta H^{\text {ads }}\right.$ is generally negative $)$, it is difficult to predict how the overall reaction rate will be influenced by temperature. But anyhow, if the activation energy for the surface reaction is larger than the sum of the adsorption enthalpies, the reaction rate will increase with temperature. On the other hand, when $E_{\text {act }}$ is smaller than the sum of the adsorption enthalpies, the overall rate decreases with increasing temperature. Since the adsorption enthalpies are large, the latter reaction rate behaviour will most probably take place. However, when the temperature is too low it is possible that the reaction kinetics will become rate limiting so that the reaction rate decreases with decreasing temperature.

The deposition of $\mathrm{ZrO}_{2}$ can be described by the following mass balance equation, remembering that the pore radius decreases as the thickness of the deposit increases:

$\frac{\mathrm{d} r}{\mathrm{~d} t}=-R_{\mathrm{surf}}\left(\frac{M W}{\rho}\right)_{\mathrm{ZrO}_{2}}$.

The reaction rate of species $i\left(\mathrm{ZrCl}_{4}\right.$ or $\left.\mathrm{H}_{2} \mathrm{O}\right), R_{i}$, defined per unit pore volume, is correlated via the cylindrical pore model to the formation rate of $\mathrm{ZrO}_{2}$, $R_{\text {surf }}$, defined per unit pore surface:

$2 \pi r \mathrm{~d} z R_{\text {surf }}=\pi r^{2} \mathrm{~d} z\left(R_{i} / n_{i}\right)$.

Insertion of eqs. (2), (8) and (11) into eq. (1) gives:

$$
\begin{aligned}
& \frac{\mathrm{d}\left([i] r^{2}\right)}{\mathrm{d} t}=\frac{2}{3} \frac{\epsilon}{\tau} v_{i} \frac{\mathrm{d}}{\mathrm{d} z}\left(r^{3} \frac{\mathrm{d}[i]}{\mathrm{d} z}\right)-2 n_{i} R_{\text {surf }} r, \\
& i=\mathrm{ZrCl}_{4} \text { or } \mathrm{H}_{2} \mathrm{O} .
\end{aligned}
$$

Solving eqs. (10) and (12) simultaneously would give the deposition profile, i.e. the pore radius as a function of axial position and time. The initial condition for eq. (10) is straightforward: the pore has its initial radius as the process starts; $r=r_{0}$ at $t=0$. Boundary conditions for eq. (12) are somewhat difficult; chemical engineering shows that the concentration of the reactants at the respective pore entrances $\left(\left[\mathrm{H}_{2} \mathrm{O}\right]_{z=0}\right.$ and $\left.\left[\mathrm{ZrCl}_{4}\right]_{z=L}\right)$ is equal to the concentration in the sources; the resistance for the reactants to move into the pore is negligibly small. The reactant concentrations at the pore exits $\left(\left[\mathrm{H}_{2} \mathrm{O}\right]_{z=L}\right.$ and $\left.\left[\mathrm{ZrCl}_{4}\right]_{z=0}\right)$ are somewhat harder to determine. So in the modelling these pore exit concentrations are considered as parameters. Possibilities are (1) $[i]=0$; (2) $[i]$ has a certain, nonzero value; $(3) \mathrm{d}[i] / \mathrm{d} z=0$. 


\subsection{Numerical solution}

Because the pore radius varies spatially and temporally during deposition, it is very difficult to solve eqs. (10) and (12) analytically. In the numerical solution, which is now performed, the differential equations and the boundary conditions are first transformed into a dimensionless form. The so introduced dimensionless variables are shown in table 1. Since the mass balances of eq. (10) reach equilibrium much faster than the evolution of the deposition, eq. (10) will be converted into its steady state version (i.e. $\left.\mathrm{d}\left([i] r^{2}\right) / \mathrm{d} t=0\right)$. The resulting dimensionless equations are:

$$
\begin{gathered}
\frac{\phi^{2} r_{0}^{2}}{L^{2}} \frac{\mathrm{d}^{2} X_{\mathrm{ZrCl}_{4}}}{\mathrm{~d} \xi^{2}}+3 \frac{\phi r_{0}^{2}}{L^{2}} \frac{\mathrm{d} \phi}{\mathrm{d} \xi} \frac{\mathrm{d} X_{\mathrm{ZrCl}_{4}}}{\mathrm{~d} \xi} \\
-2 n_{\mathrm{ZrCl} 4} \Phi X_{\mathrm{ZrCl} 4}^{N} X_{\mathrm{H}_{2} \mathrm{O}}^{M}=0 \\
\frac{\phi^{2} r_{0}^{2}}{L^{2}} \frac{\mathrm{d}^{2} X_{\mathrm{H}_{2} \mathrm{O}}}{\mathrm{d}^{2}}+3 \frac{\phi r_{0}^{2}}{L^{2}} \frac{\mathrm{d} \phi}{\mathrm{d} \xi} \frac{\mathrm{d} X_{\mathrm{H}_{2} \mathrm{O}}}{\mathrm{d} \xi} \\
-2 n_{\mathrm{H}_{2} \mathrm{O}} \Phi \chi X_{\mathrm{ZrCl}_{4}}^{N} X_{\mathrm{H}_{2} \mathrm{O}}^{M}=0 \\
\frac{\mathrm{d} \phi}{\mathrm{d} \theta}=-\frac{L}{r_{0}} \Phi \gamma X_{\mathrm{ZrCl}_{4}}^{N} X_{\mathrm{H}_{2} \mathrm{O}}^{M} .
\end{gathered}
$$

The boundary conditions are also converted into their dimensionless form. This set of differential equations is simultaneously solved by the orthogonal collocation numerical method. This method is extensively described in [16]. Here, an outline is given. The variables $X_{\mathrm{ZrCl} 4}$ and $X_{\mathrm{H}_{2} \mathrm{O}}$ along the pore axes are approximated by a Lagrange polynomial which has the following form:

$X(\xi)=\sum_{j=1}^{N_{\mathrm{ic}}+2} L_{j}(\xi) X_{j}$

$N_{\text {ic }}$ is the number of the internal collocation points (here is taken that $N_{\mathrm{ic}}=12$ ), and $X_{j}$ is the (yet unknown ) value of $X$ at collocation point $\xi_{j}$ along the pore axial direction. The collocation points $\xi_{j}$ are the roots of orthogonal polynomials as defined by [16]. The essence of the orthogonal collocation method is, that the set $X_{j}\left(X_{\mathrm{ZrCl}_{4}, j}\right.$ or $\left.X_{\mathrm{H}_{2} \mathrm{O}, j}\right)$ is determined by satisfying the set of differential equations exactly at the internal collocation points $\xi_{j}$. From eq. (16), the first and second derivatives of $X_{i}$ can be discretized at the collocation points. These discretized derivatives are inserted into eqs. (13) and (14); together with the incorporation of boundary conditions this results in two sets (for $\mathrm{ZrCl}_{4}$ and $\mathrm{H}_{2} \mathrm{O}$ ) of $N_{\mathrm{ic}}$ algebraic equations with $N_{\text {ic }}$ unknown variables. These systems of pseudo-linear algebraic equations (nonlinearity only enters in the last term on the left hand

Table 1

Variables and parameters used in the CVD model.

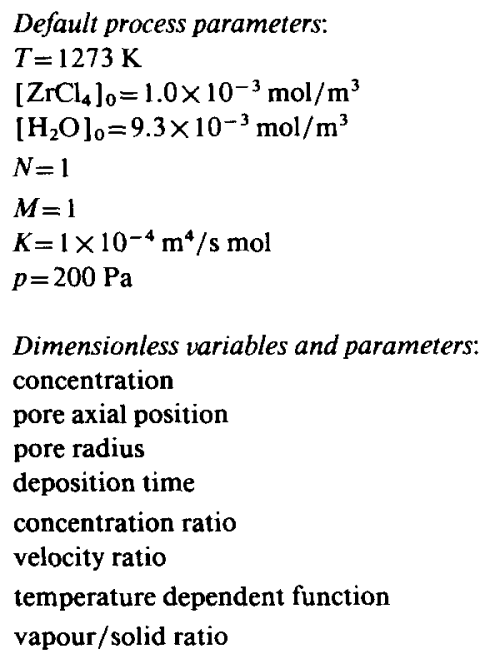

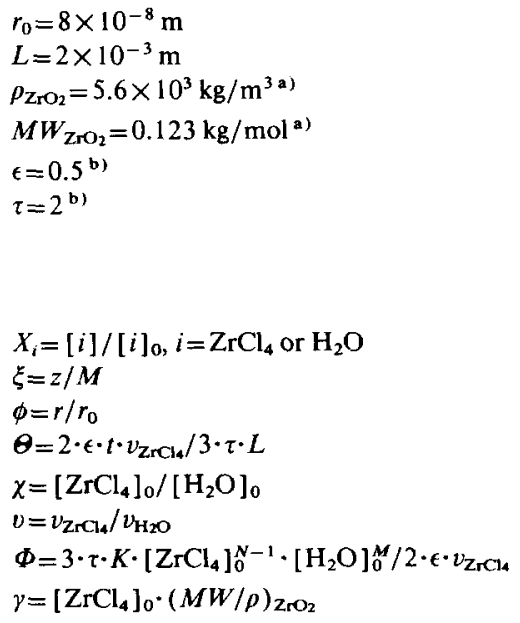

a) Ref. [17]; ') Ref. [18]. 
side of eq. (13) and (14)) are solved in the way described in [16]. The deposition profile at deposition time $\theta$ at the different collocation points is computed by inserting the calculated values of $X_{j}$ into the discretized form of eq. (15) and integrating this equation by Euler's method. The time step is evaluated so that it corresponds to an increment of $\phi$ of about $1 / 200$. This whole procedure is repeated until the pore is closed, i.e. the minimum value of $\phi$ is $0.0 \pm 0.005$.

\subsection{Numerical results}

Because an aim of this investigation is to compare modelling results with experimental results, default values for (experimental) process parameters are also used in the model (see table 1 ).

The results of the modelling are shown here in several deposition profile graphs, in which the (dimensionless) local pore radius is given as a function of the (dimension-less) axial pore position. In fig. 2, the influence of the boundary conditions is investigated (the rest of the parameters is default). Since the deposition profile is the same when the boundary condition for the $\mathrm{ZrCl}_{4}$ concentration at the pore exit $(z=0)$ is $\left[\mathrm{ZrCl}_{4}\right]=0$ or $\mathrm{d}\left[\mathrm{ZrCl}_{4}\right] / \mathrm{d} z=0$, it seems that $\mathrm{ZrCl}_{4}$ does not diffuse entirely to the pore exit.
This is consistent with the experiments, since $\mathrm{ZrO}_{2}$ has never been found at the $\mathrm{H}_{2} \mathrm{O}$ side [7]. On the other hand, a large difference results between the cases where the $\mathrm{H}_{2} \mathrm{O}$ concentration is zero or nonzero at the pore exit $(z=\mathrm{L})$. When the $\mathrm{H}_{2} \mathrm{O}$ concentration is not equal to zero, the maximum deposition location is at the pore end, while with zero $\mathrm{H}_{2} \mathrm{O}$ concentration at the pore end the maximum location is shifted inside the pore. In the following model calculations the $\mathrm{ZrCl}_{4}$ concentration at $z=0$ is assumed to be zero, and the derivative of the $\mathrm{H}_{2} \mathrm{O}$ concentration at $z=\mathrm{L}$ is also zero.

The influence of temperature is considered in fig. 3. Here the reaction rate constant $K(T)$ is varied. From theory it is found that when the activation energy of the surface reaction is smaller than the sum of the adsorption enthalpies (which is most probably the case in the Langmuir-Hinshelwood mechanism ), the reaction rate will decrease with increasing temperature. In the case of a gas phase reaction, in which we only deal with an activation energy, $K$ will increase with temperature. From fig. 3 it can be seen that when $K$ increases (lower temperature as $E_{\text {act }}$ is smaller than the sum of adsorption enthalpies), the deposition zone gets smaller. Comparison with experimental results (see next section) may confirm the Langmuir-Hinshelwood behaviour.

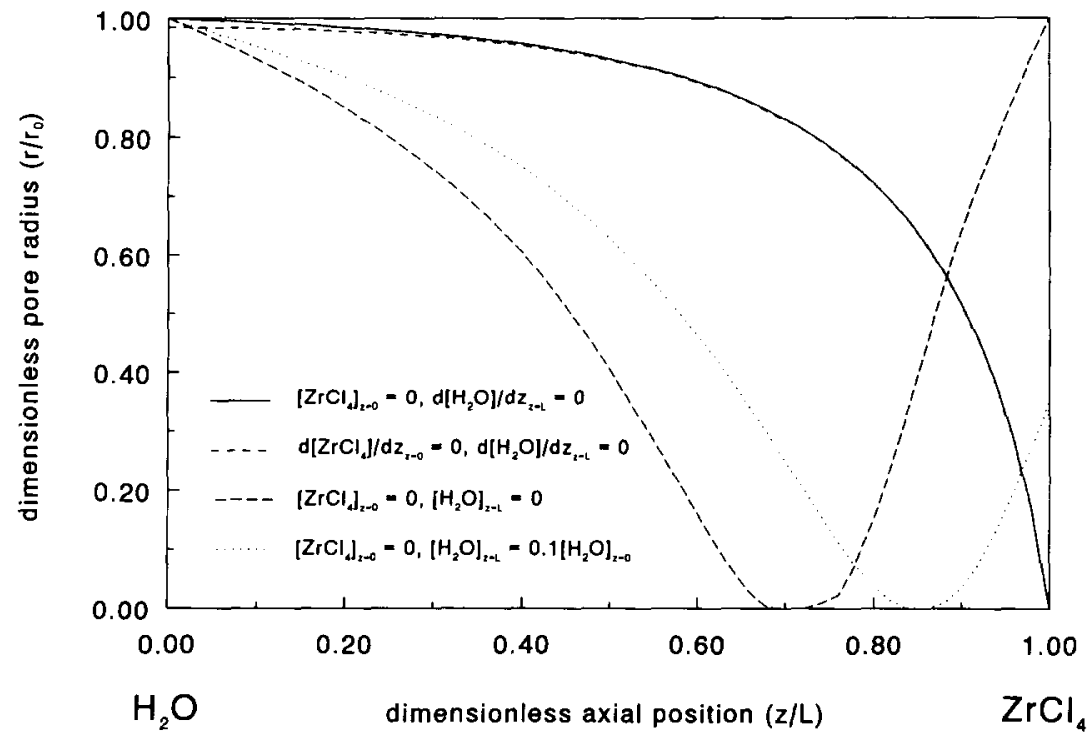

Fig. 2. Effects of the boundary conditions on the simulated deposition profile. 


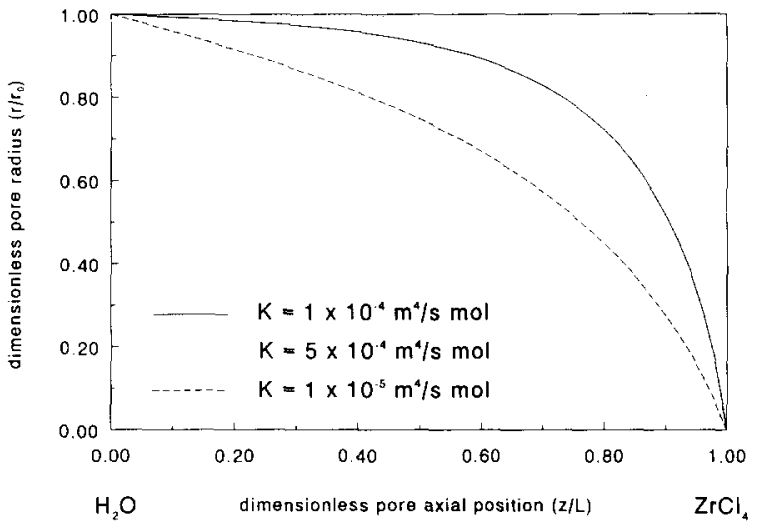

Fig. 3. Effects of the reaction rate constant $K$ on the simulated deposition profile.

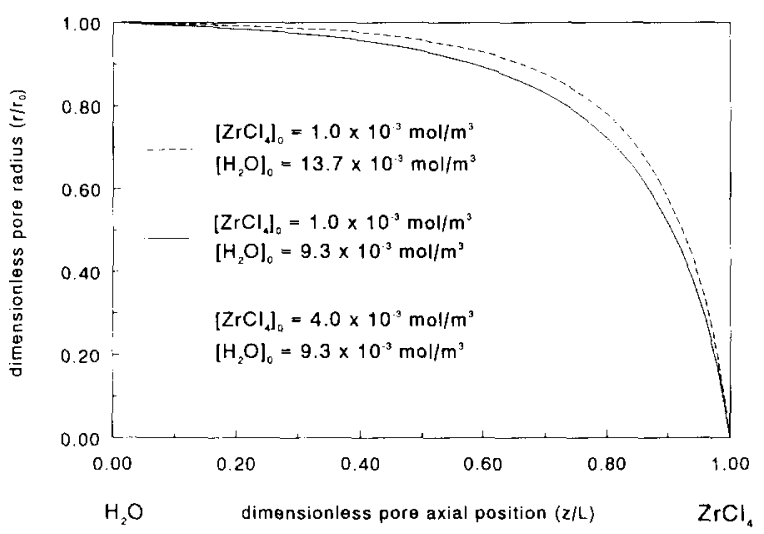

Fig. 4. Effects of the reactant concentrations on the simulation deposition profile.

The influence of the reactant concentrations is also investigated. The results are shown in fig. 4 . In the case of a non-zero order reaction in both reactants, the influence on the deposition profile is well noticeable. A larger $\mathrm{ZrCl}_{4}$ concentration will result in a more broadened deposition zone, and so will a smaller $\mathrm{H}_{2} \mathrm{O}$ concentration.

\section{Experimental results and discussion}

The way in which CVD/EVD experiments have been performed, is described extensively elsewhere [7]. Default process conditions are shown in table 1. Several zirconia (in practice zirconia/yttria) de- posited $\alpha$-alumina samples have been investigated using a Jeol JSM-35CF scanning electronic microscope connected with a Kevex Delta-class EDX analyzer for energy dispersive X-ray analysis of the elements, to obtain an experimental deposition profile inside the porous substrate. Samples have been cut (cross sectional) and the cross sectional surface was sputtered with carbon to make it electrically conducting. Element scans have been performed on $\mathrm{Al}$ and $\mathrm{Zr}$. The results are shown in figs. 5 and 6. For surveyability, only the $\mathrm{Zr}$ profiles are shown (in arbitrary units). The zero level on the $x$-axis is the edge of the original $\alpha$-alumina sample, so the profile is the real penetration in the porous substrate. In all cases the maximum deposition location is at the pore end

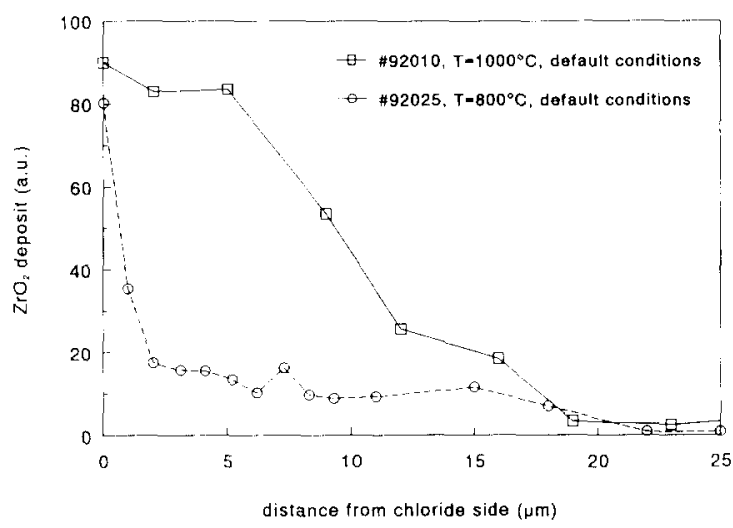

Fig. 5. Effects of the temperature on the deposition profile of $\mathrm{ZrO}_{2}$ inside an $\alpha$-alumina substrate, measured by EDX.

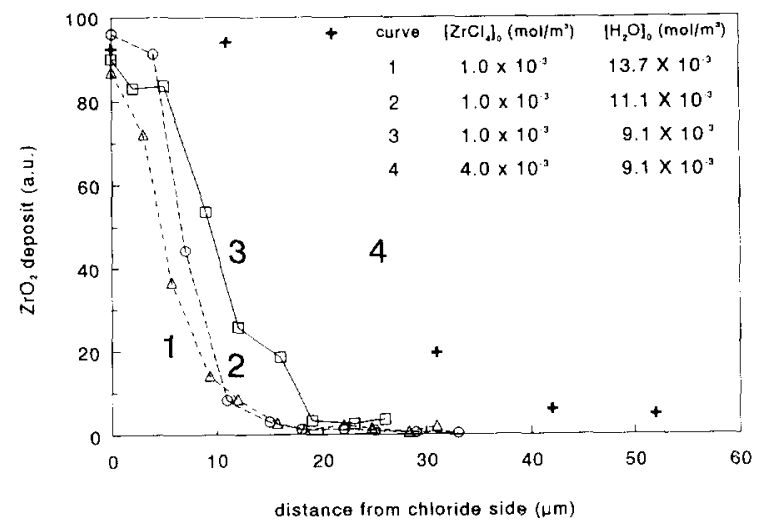

Fig. 6. Effects of the reactant concentrations on the deposition profile of $\mathrm{ZrO}_{2}$ inside an $\alpha$-alumina substrate, measured by EDX. 
directed towards the metal chloride side.

Fig. 5 shows the deposition profile of $\mathrm{Zr}$, deposited at $800^{\circ} \mathrm{C}$ and $1000^{\circ} \mathrm{C}$ under default conditions. At both temperatures a typical profile is shown; doubles have been made. At $1000^{\circ} \mathrm{C}$, the pore closing plug is considerably broadened $(\sim 15 \mu \mathrm{m})$ compared to that at $800^{\circ} \mathrm{C}(\sim 3 \mu \mathrm{m})$. This is consistent with the Langmuir-Hinshelwood model in which the activation energy for surface reaction is smaller than the sum of adsorption enthalpies. However, it seems that $\mathrm{Zr}$ has penetrated into the pores up to $20 \mu \mathrm{m}$ at $800^{\circ} \mathrm{C}$, which can be seen in fig. 5 as a kind of plateau inside the pores. Its origin may be due to $\mathrm{ZrCl}_{4}$ being diffused inside the pores during heating up of the reactor system, which has been reacted to $\mathrm{ZrO}_{2}$ on application of $\mathrm{H}_{2} \mathrm{O}$. Experiments are now being performed to investigate whether this "pre-deposition" is systematic or a process property.

Fig. 6 shows the influence of the reactant concentrations on the deposition profile. All deposition experiments have been performed at $1000^{\circ} \mathrm{C}$; doubles have been made. In the figure it can be seen that an increase in the water concentration gives a smaller deposition zone. An increase in the $\mathrm{ZrCl}_{4}$ concentration gives a more broadened deposition zone. These results are consistent with the model. It is shown, that the deposition profile is influenced by the concentration of both reactants, resulting in a reaction rate of the form $R=\mathrm{K}\left[\mathrm{ZrCl}_{4}\right]^{N}\left[\mathrm{H}_{2} \mathrm{O}\right]^{M}$ in which $N$ and $M$ are both not zero. In all cases, the maximum deposition location is at the pore end of the metal chloride side, which indicates that the water concentration at the pore end $(z=\mathrm{L})$ is not zero.

A good qualitative comparison exists between the modelling results and the experimental EDX results, since the profiles show the same trends in all cases, if a Langmuir-Hinshelwood mechanism is assumed and if the activation energy for the surface reaction is smaller than the sum of the adsorption enthalpies. In the case of a gas phase reaction inside the pores, another temperature dependence of the deposition profiles is expected. On a quantitative base, better modelling results can be obtained when the exact values of the kinetic parameters (reactant orders, $E_{\text {act }}$, $\left.\Delta H_{\text {ads }}\right)$ are known.

\section{Conclusions}

Qualitative comparison of the modelling results of the CVD process and experimental EDX profiles shows that the Langmuir-Hinshelwood mechanism is most probably the dominating mechanism for deposition of $\mathrm{ZrO}_{2}$ inside the porous ceramic substrates. It is also shown that the deposition profile at the chloride side of the substrate is dependent on the concentrations of both reactants, $\mathrm{ZrCl}_{4}$ and $\mathrm{H}_{2} \mathrm{O}$.

For obtaining ultra thin layers of zirconia/yttria it is preferable to perform deposition experiments at lower temperatures $\left(\right.$ e.g. $800^{\circ} \mathrm{C}$ ). In this case it is shown that the pore closing plug penetrates less deep into the substrate than at higher temperatures.

\section{Acknowledgement}

This investigation was supported by the Netherlands Foundation for Chemical Research (SON), project nr. 700-332-004, with financial aid from the Netherlands Organization for Scientific Research (NWO).

\section{References}

[1] A.O. Isenberg, in: Proc. Symp. Electrode Materials, Processes for Energy Conversion and Storage, eds. J.D.E. McIntyre, S. Srinivasan and F.G. Will, Vol. 77-6 (The Electrochem. Soc. Inc., Princeton, NJ, 1977) pp. 572-583.

[2] G. Dietrich and W. Schäfer, Int. J. Hydrogen Energy 9 (1984) 747.

[3] M.F. Carolan and J.N. Michaels, Solid State Ionics 25 (1987) 207.

[4] Y.S. Lin, K.J. de Vries and A.J. Burggraaf, J. Phys. Colloq. C5 50 (1989) 861.

[5] Y.S. Lin and A.J. Burggraaf, Chem. Eng. Sci. 46 (1991) 3067.

[6] Y.S. Lin and A.J. Burggraaf, AIChE J. 38 (1991) 445.

[7] L.G.J. de Haart, Y.S. Lin, K.J. de Vries and A.J. Burggraaf, J. Eur. Ceram. Soc. 8 (1991) 59.

[8] C.J. Geankoplis, Mass Transport Phenomena (Holt, Rinehart \& Winston, New York, 1972) p. 152.

[9] P.W. Atkins, Physical Chemistry (Oxford University Press, Oxford, 1978) p. 800.

[10] L.K. Doraiswamy and M.M. Sharma, Heterogeneous Reactions: Analysis, Examples, and Reactor Design, Vol. 1 (Wiley, New York, 1984) p. 51. 
[11] A.J. Burggraaf, H.J.M. Bouwmeester, B.A. Boukamp, R.J.R. Uhlhorn and V. Zaspalis, in: Science of Ceramic Interfaces, ed. J. Nowotny (Elsevier, Amsterdam, 1991) pp. 525-568.

[12] R.E. Cunningham and R.J.J. Williams, Diffusion in Gases and Porous Media (Plenum Press, New York, 1980) p. 76.

[13] J.M. Smith, Chemical Engineering Kinetics (McGraw-Hill, New York, 1981) p. 453.

[14] E.A. Mason and A.P. Malinauskas, Gas Transport in Porous Media: The Dusty Gas Model (Elsevier, Amsterdam, 1983) p. 23.

[15] K.J. Laidler, Chemical Kinetics (Harper \& Row, New York, 1987) p. 249.

\section{List of symbols}

$\chi \quad$ concentration ratio $(-)$

$D_{\mathrm{Kn}, i}$ Knudsen diffusion coefficient for reactant $i\left(\mathrm{~m}^{2} / \mathrm{s}\right)$

$\varepsilon \quad$ porosity of the substrate $(-)$

$E_{\text {act }}$ activation energy for surface reaction $(\mathrm{kJ} /$ mol)

$\gamma \quad$ vapour/solid ratio ( - )

$\Delta H_{i}{ }^{\text {ads }}$ adsorption enthalpy for reactant $i(\mathrm{~kJ} / \mathrm{mol})$

[i] concentration of reactant $i\left(\mathrm{~mol} / \mathrm{m}^{3}, i=\mathrm{ZrCl}_{4}\right.$, $\mathrm{H}_{2} \mathrm{O}$ )

$[i]_{0}$ concentration of reactant $i$ in the source $(\mathrm{mol} /$ $\mathrm{m}^{3}$ )

[ $\left.i_{\text {ads }}\right]$ concentration of reactant $i$, adsorbed on pore surface $\left(\mathrm{mol} / \mathrm{m}^{3}\right)$

$J_{i} \quad$ diffusive flux of species $i\left(\mathrm{~mol} / \mathrm{m}^{2} \mathrm{~s}\right)$

$k_{\text {surf }}$ surface reaction rate constant $\left(\mathrm{m}^{3 N+3 M-2} /\right.$ $\mathrm{s} \cdot \mathrm{mol}^{N+M-1}$ )

$K$ lumped reaction rate constant $\left(\mathrm{m}^{3 N+3 M-2} /\right.$ $s \cdot \mathrm{mol}^{N+M-1}$ )

$K_{i} \quad$ adsorption equilibrium constant for reactant $i(-)$
[16] J. Villadsen and M. Michelsen, Solution of Differential Equation Models by Polynomial Approximation (Prentice Hall, Englewood Cliffs, NJ, 1978) pp. 105-134, 212-214.

[17] R.C. Weast, ed., Handbook of Chemistry and Physics, 55th ed. (CRC Press, Cleveland, OH, 1974/75) B-156.

[18] R.J. v. Vuren, B.C. Bonekamp, K. Keizer, R.J.R. Uhlhorn, H.J. Veringa and A.J. Burggraaf, in; High Tech Ceramics, ed. P. Vincenzini (Elsevier, Amsterdam, 1987) pp. 22352245.

$L \quad$ thickness of substrate ( $\mathrm{m}$ )

$M$ reaction order with respect to $\mathrm{H}_{2} \mathrm{O}$

MW molar weight $(\mathrm{kg} / \mathrm{mol})$

$N$ reaction order with respect to $\mathrm{ZrCl}_{4}$

$N_{\text {ic }} \quad$ number of internal collocation points

$n_{i} \quad$ stoichiometric coefficients ( - )

$R_{i} \quad$ reaction rate of reactant $i\left(\mathrm{~mol} / \mathrm{m}^{3} \mathrm{~s}\right)$

$R_{\text {surf }}$ formation rate of $\mathrm{ZrO}_{2}\left(\mathrm{~mol} / \mathrm{m}^{2} \mathrm{~s}\right)$

$r$ pore radius $(\mathrm{m})$

$r_{0} \quad$ initial pore radius $(\mathrm{m})$

$\phi \quad$ dimensionless pore radius $(-)$

$\Phi$ temperature dependent function ( - )

$\rho$ density $\left(\mathrm{kg} / \mathrm{m}^{3}\right)$

$t \quad$ deposition time (s)

$\theta$ dimensionless deposition time $(-)$

$\tau \quad$ tortuosity of the substrate ( - )

$v_{i} \quad$ velocity of reactant $i(\mathrm{~m} / \mathrm{s})$

$v \quad$ velocity ratio $(-)$

$X_{i}$ dimensionless concentration (-)

$z \quad$ axial position on the pore $(\mathrm{m})$

$\xi \quad$ dimensionless pore axial position (-) 